\title{
Gamma Ray Induced Macro Mutants in Sesame (Sesamum indicum L.)
}

\author{
Sruba Saha* and Amitava Paul
}

\author{
Department of Genetics and Plant Breeding and Crop Physiology, Institute of Agriculture \\ (Palli Siksha Bhavana), Visva-Bharati, Sriniketan, West Bengal, India \\ *Corresponding author
}

\begin{abstract}
A B S T R A C T
Keywords

Sesame, Gamma

rays, Selection, $\mathrm{M}_{2}$ generation, Macromutation, $\mathrm{M}_{3}$ generation.

Article Info

Accepted:

21 September 2017

Available Online:

10 October 2017

An experiment was made to determine the spectrum and frequency of different macro mutants induced by gamma rays on sesame with two genetic backgrounds. Treatment concerned seeds of the two cultivars Rama and Tillotoma, predominantly grown in West Bengal were irradiated by five doses $(250,300,350,400$ and $450 \mathrm{~Gy})$ of gamma rays at the Bhaba Atomic Research Centre (BARC), Trombey. Irradiated seeds along with control (unirradiated) were sown in University experimental farm, Visva-Bharati during pre-kharif in 2015, 2016 and 2017 to grow $\mathbf{M}_{1}, \mathbf{M}_{2}$ and $\mathbf{M}_{3}$ generation, respectively. All putative mutants were selected from $\mathrm{M}_{2}$ population were grown in the $\mathrm{M}_{3}$ generation to confirm their breeding behavior. A wide spectrum of the mutants under studies i.e. shattering resistance, determinate growth habit, early matured types etc. were observed. Among the all traits, shattering resistant and early matured type mutants were induced from both cultivars at each applied doses. Depends upon all traits under studies, Rama had the highest mutation frequency $\left(8.64 \times 10^{-3}\right)$ followed by Tillotoma $\left(6.28 \times 10^{-3}\right)$. These results indicated that selection of unique mutants is not a matter of chance; rather it depends upon population size, the response of the cultivars to effective mutagenesis and careful screening.
\end{abstract}

\section{Introduction}

Sesame (Sesamum indicum $\mathrm{L} . ; 2 \mathrm{n}=26$ ) is rich in limiting amino acid methionin, and provides a valuable source of nutritious protein as well as high quality oil that resists oxidative rancidity due to the presence of the phenylpropanoid, lignins, sesamin and sesamolin. In India, it is the fifth important edible oil seed crop after groundnut, rapeseedmustard, sunflower and soybean with the annual average production around $6,80,000$ metric tons, though, the productivity of sesame stands alarmingly poor comparing to other oil yielding crops. As a quality oil seed crop, it can reduce the shortage of other edible oil production not only in India but also in major sesame growing countries in the world, if the production and productivity are enhanced using modern breeding techniques like mutation breeding with irradiation.

Yet, sesame is unimproved in India and many collections have been made from local land races, but little genetic information is available which can lead to its utilization in breeding programmes. A number of factors affecting sesame improvement programmes have been identified. Firstly, the germplasm of sesame is not as large as in other crops 
(Ashri, 1981). Secondly, the architecture of sesame is poorly adapted to modern farming system because of its indeterminate growth habit, sensitivity to wilting under intensive management and seed shattering at maturity (Cagirgan, 2001; Uzun and Cagirgan, 2006). Although many research has been made on through irradiation and chemical mutagen to improve: yield (Wongyai et al., 2001), capsules number, leaves maturation, male sterility, plant architecture (Cagirgan, 2006), seed size and seed color (Hoballah, 2001), narrow leaf (Sengupta and Dutta, 2005), resistant to fusarium wilt (Silme, 2010) and early matured plant (Mensah et al., 2007), however, studies on growth habit, maturity, shattering habit and plant architecture are still scanty.

Indeterminate growth habit is a challenge for sesame breeders. Due to continual flowering and non-uniform ripening of the capsules, it is difficult to decide when to harvest the seeds. Flowering can continue over a period of 2 months if the environmental conditions are favorable for sesame growth (Cagirgan, 2006). It has become an active area of research after the discovery of "dt-45" by Ashri (1981), which was the first determinate mutant type, selected from $\mathrm{M}_{2}$ population of the Israeli sesame cultivar "No-45", irradiated with 500 Gy Gamma rays. It is encouraging that Cagirgan induced six such mutants whose breeding value and affinity to the 'id' allele are now under study in Turkey. Seed shattering is also a major issue to lose the production and productivity, early harvesting causes low seed yield, and poor quality due to the consist of immature seeds on the top of the plant. The late harvesting too reduces seed yield from the lower matured capsule because of seed shattering. In addition, this crop is predominantly cultivated in state like West Bengal, India during pre-kharif season after harvest of paddy, rapeseed-mustard and potato. For more acceptances among farmers to grow sesame as catch crop in rice based cropping system, there should be easy availability of short duration early maturing (60-65 days) varieties with high yield potential which are currently lacking in this crop. To address this challenges and finding a solution, the goal of the present study has been undertaken to select determinate mutant, shatter resistant, early maturing mutant types and some desirable traits to make the crop suitable for multiple cropping system, to ensure higher yield and possibly create to choose new ideotypes in further generation.

\section{Materials and methods}

The study was carried out at the University Agriculture Farm of Visva-Bharati, Sriniketan $\left(23^{0} 29^{\prime} \mathrm{N}\right.$ latitude and $87^{\circ} 42^{\prime} \mathrm{E}$ longitudes $)$ in pre-kharif season of 2015, 2016 and 2017. The elevation of the site is $58.9 \mathrm{~m}$ above the mean sea level with sub-humid, sub-tropical monsoon climate and lateritic soil.

\section{Plant materials}

Two popular sesame cultivars, from West Bengal, Rama and Tillotoma were taken for the present study (Table 1).

\section{Gamma irradiation}

10,000 dry, uniform and healthy seeds of these two genotypes of sesame were irradiated using ${ }^{60} \mathrm{Co}$ (Cobalt 60) gamma source with different doses $(250,300,350$, $400,450 \mathrm{~Gy}$ ) of gamma rays at the Bhabha Atomic Research Centre (BARC), Trombay, India.

\section{Field Experiment}

Irradiated seeds $\left(\mathrm{M}_{0}\right)$ along with the controls (un-irradiated) were sown in the field in a split plot design with three replications keeping plant to plant and row to row distance of 10 and $30 \mathrm{~cm}$, respectively during prekharif season of 2015. Four to five capsules of 
each $\mathrm{M}_{1}$ plants against all the treatments were collected separately to rise the $\mathrm{M}_{2}$ generation. Individual plant to progeny rows were grown in $\mathrm{M}_{2}$ generation (pre-kharif 2016) keeping row to row and plant to plant distance at 30 $\mathrm{cm}$ and $10 \mathrm{~cm}$, respectively. Immediately after germination, various types of chlorophyll mutation (albina, chlorina, xantha) were recorded to study the mutagenic effect of different doses. Throughout the experiment, all putative mutants were tagged and selected. The characteristics of the desirable mutants were: early matured, shatter resistant, determinate growth habit, more number of capsules/plant, multi locules capsule, capsule length, multi capsules/leaf axil or cluster type, more seed weight, dwarf and monostem types. Potential mutants selected from two cultivars in 2016 seasons were grown in $\mathrm{M}_{3}$ generation to confirm breeding behavior during pre- kharif 2017 in progeny rows keeping row to $30 \mathrm{~cm}$ and plant to plant $10 \mathrm{~cm}$. In every generation, other agronomic package, practices and plant protection measures were taken throughout the experiment.

The mutation frequencies for progeny were estimated by dividing the total number of mutants confirmed by the total number of $\mathrm{M}_{2}$ plants (Gaul, 1964).

\section{Results and Discussion}

\section{Mutation spectrum and frequency over cultivars and doses}

In total $103134 \mathrm{M}_{2}$ plants were grown under experiment. $\mathbf{M}_{2}$ population sizes for each cultivar are given in Table 2. Differences were observed between cultivars for mutation frequency in each dose. The viable mutation frequency indicated a maximum rate for Rama at 300 Gy $\left(8.90 \times 10^{-3}\right)$ followed by Tillotoma at 350Gy $\left(1.28 \times 10^{-2}\right)$. Between two cultivars, maximum desirable mutants were selected from Rama (455) with highest frequency $\left(8.64 \times 10^{-3}\right)$. In $\mathrm{M}_{1}$ generation, radio sensitivity test confirmed that Tillotoma was more sensitive than Rama. The reduction of plant population in $\mathrm{M}_{2}$ generation with increasing of doses and it differed between two cultivars also confirmed this finding. Though, high mutation frequency was observed in both cultivars, Rama showed greater frequency in respect to all characters than Tillotoma. In this experiment maximum viable mutant types were lies in moderate dose (250 to $350 \mathrm{~Gy}$ ) which indicate the selection efficiency of these doses. Several researchers (Cagirgan, 2007; Van-Zanten, 2001; Diouf, 2010) also stated that 300 to 400 Gy of gamma rays is effective enough to induced mutation from any sesame cultivar. The present findings are closely agreed to the previous research work in sesame.

\section{Selection of individual macro mutants}

\section{Shattering resistant types}

52 mutants were found with shatter resistance for both cultivars. The highest mutation frequency for this category was observed in Rama $\left(5.13 \times 10^{-4}\right)$ with 27 mutants followed by in Tillotoma $\left(4.95 \times 10^{-4}\right)$ with 25 mutants (Table 3) (Fig. 2b). Reduction of seed loss at maturity and harvest by developing cultivars with shattering resistant capsules is the key to successful cultivation of sesame. A spontaneous indehiscent "id" allele was discovered by Langham (1946) in Venezuela. Later on, a peer of scientists (Wongyai et al., 1997; Diouf, 2010), found delayed, closed capsule and semi shattering mutants similar to our cases.

\section{Early maturing types}

Earliness has been an important objective of breeding in several crops under different ecological conditions. The early types have the possibilities to permit multiple cropping systems, escape from late season pests. The 
leaf shapes of early matured plant were narrow (Fig. 2a) though the un-irradiated plant had broad leaves (Fig. 1). 37 early matured mutants were selected in both cultivars from all doses, from which the maximum mutation frequency obtained in Rama (4.56 x 10 $0^{-4}$ ) (Table 3). Early maturing and high-yielding sesame have been developed by using $\mathrm{NaN}_{3}$ and colchicines, and Mensah et al., (2007) found that $0.0625 \%$ $\mathrm{NaN}_{3}$ and $0.125 \%$ colchicine were the most efficient concentration for inducing mutations in sesame.

\section{Determinate types}

19 determinate mutants were isolated, there of 10 were in Rama having highest mutation frequency $\left(1.96 \times 10^{-3}\right)$ and 9 were in
Tillotoma background (Table 3) (Fig. 2c). After the invention of "dt-45" by (Ashri, 1981), Cagirgan 2006, confirmed 6 true botanical mutant with determinate growth habit in sesame, though the breeding value and affinity of confirmed mutants are under study.

\section{Dwarf types}

To start a breeding program of any crop wind should be taken into consideration due to possibility of lodging. Generally, tall plants bearing high capsules are prone to lodging, whereas, dwarf plants are more suitable in these conditions. 99 dwarf type mutants were selected and confirmed in $\mathrm{M}_{2}$ and $\mathrm{M}_{3}$ generation respectively, whereas 53 from Rama (1.01 x 10-3) and 46 from Tillotoma (9.11 x 10-4) counterparts (Table 3 ).

Table.1 Some properties of two sesame cultivars

\begin{tabular}{|c|c|c|c|c|c|}
\hline $\begin{array}{c}\text { Name of } \\
\text { Cultivar }\end{array}$ & $\begin{array}{c}\text { Selected } \\
\text { from }\end{array}$ & $\begin{array}{c}\text { Seed coat colours and } \\
\text { surface conditions }\end{array}$ & Size & $\begin{array}{c}\text { Days to } \\
\text { maturity }\end{array}$ & $\begin{array}{c}\text { 1000 Seed } \\
\text { weight }(\mathbf{g})\end{array}$ \\
\hline Tillotoma & West Bengal & Brown, rough and dull & $\begin{array}{c}\text { Medium, } \\
\text { bold }\end{array}$ & 90 to 100 & 3.0 \\
\hline Rama & West Bengal & $\begin{array}{c}\text { Brown, rough and } \\
\text { glossy }\end{array}$ & $\begin{array}{c}\text { Medium, } \\
\text { bold }\end{array}$ & 100 to 110 & 3.1 \\
\hline
\end{tabular}

Table.2 Total spectrum and frequencies of induced mutants in two sesame cultivars

\begin{tabular}{|c|c|c|c|c|}
\hline \multirow{2}{*}{ Cultivar } & $\begin{array}{c}\text { Dose } \\
(\mathbf{G y})\end{array}$ & $\begin{array}{c}\text { No. of M2 } \\
\text { studied }\end{array}$ & No. of mutants & $\begin{array}{c}\text { Mutation } \\
\text { frequency }\end{array}$ \\
\hline \multirow{4}{*}{ Rama } & 250 & 14299 & 51 & $3.57 \times 10^{-3}$ \\
\cline { 2 - 5 } & 300 & 12926 & 115 & $8.90 \times 10^{-3}$ \\
\cline { 2 - 5 } & 350 & 9697 & 154 & $1.59 \times 10^{-2}$ \\
\cline { 2 - 5 } & 400 & 8226 & 99 & $1.20 \times 10^{-2}$ \\
\cline { 2 - 5 } & 450 & 7518 & 36 & $4.79 \times 10^{-3}$ \\
\cline { 2 - 5 } & Total & $\mathbf{5 2 6 6 6}$ & $\mathbf{4 5 5}$ & $\mathbf{8 . 6 4}^{-3} \mathbf{1 0}$ \\
\hline \multirow{4}{*}{ Tillotoma } & 250 & 15645 & 47 & $3.00 \times 10^{-3}$ \\
\cline { 2 - 5 } & 300 & 10425 & 60 & $5.76 \times 10^{-3}$ \\
\cline { 2 - 5 } & 350 & 8383 & 107 & $1.28 \times 10^{-2}$ \\
\cline { 2 - 5 } & 400 & 8057 & 60 & $7.45 \times 10^{-3}$ \\
\cline { 2 - 5 } & 450 & 7958 & 45 & $5.65 \times 10^{-3}$ \\
\cline { 2 - 5 } & Total & $\mathbf{5 0 4 6 8}$ & $\mathbf{3 1 7}$ & $\mathbf{6 . 2 8}^{-3} \mathbf{1 0}$ \\
\hline
\end{tabular}


Table.3 Spectrum and frequency of some promising macro mutants in Rama and Tillotoma

\begin{tabular}{|c|c|c|c|c|c|c|c|c|}
\hline Cultivar & $\begin{array}{l}\text { Dose } \\
(\mathbf{G y})\end{array}$ & $\begin{array}{c}\text { No. of } \mathrm{M}_{2} \\
\text { seedling } \\
\text { studied }\end{array}$ & $\begin{array}{l}\text { Shattering } \\
\text { resistant types }\end{array}$ & $\begin{array}{c}\text { Early maturing } \\
\text { types }\end{array}$ & $\begin{array}{c}\text { Determinate } \\
\text { types }\end{array}$ & Dwarf types & $\begin{array}{l}\text { Monostem } \\
\text { types }\end{array}$ & $\begin{array}{c}\text { More no. } \\
\text { capsules/plant } \\
\text { types }\end{array}$ \\
\hline \multirow{6}{*}{ Rama } & 250 & 14299 & $4.20 \times 10^{-4}(6)$ & $5.59 \times 10^{-4}(8)$ & $2.80 \times 10^{-4}(4)$ & $6.99 \times 10^{-4}(10)$ & $6.29 \times 10^{-4}(9)$ & -- \\
\hline & 300 & 12926 & $8.51 \times 10^{-4}(11)$ & $3.09 \times 10^{-4}(4)$ & $3.09 \times 10^{-4}(4)$ & $8.51 \times 10^{-4}(11)$ & $7.74 \times 10^{-4}(10)$ & $2.32 \times 10^{-3}(30)$ \\
\hline & 350 & 9697 & $6.19 \times 10^{-4}(6)$ & $8.25 \times 10^{-4}(8)$ & $2.06 \times 10^{-4}(2)$ & $1.55 \times 10^{-3}(15)$ & $8.25 \times 10^{-4}(8)$ & $3.61 \times 10^{-3}(35)$ \\
\hline & 400 & 8226 & $2.43 \times 10^{-4}(2)$ & $2.43 \times 10^{-4}(2)$ & -- & $1.09 \times 10^{-3}(9)$ & - & $3.16 \times 10^{-3}(26)$ \\
\hline & 450 & 7518 & $2.66 \times 10^{-4}(2)$ & $2.66 \times 10^{-4}(2)$ & -- & $1.06 \times 10^{-3}(8)$ & - & $1.60 \times 10^{-3}(12)$ \\
\hline & Total & 52666 & $5.13 \times 10^{-4}(27)$ & $4.56 \times 10^{-4}(24)$ & $1.90 \times 10^{-4}(10)$ & $1.01 \times 10^{-3}(53)$ & $5.13 \times 10^{-4}(27)$ & $1.96 \times 10^{-3}(103)$ \\
\hline \multirow{6}{*}{ Tillotoma } & 250 & 15645 & $3.84 \times 10^{-4}(6)$ & $1.28 \times 10^{-4}(2)$ & $1.28 \times 10^{-4}(2)$ & $5.75 \times 10^{-4}(9)$ & $5.75 \times 10^{-4}(9)$ & $5.75 \times 10^{-4}(9)$ \\
\hline & 300 & 10425 & $5.76 \times 10^{-4}(6)$ & $2.88 \times 10^{-4}(3)$ & $1.92 \times 10^{-4}(2)$ & $7.67 \times 10^{-4}(8)$ & -- & $1.15 \times 10^{-3}(12)$ \\
\hline & 350 & 8383 & $7.16 \times 10^{-4}(6)$ & $4.77 \times 10^{-4}(4)$ & $4.77 \times 10^{-4}(4)$ & $1.43 \times 10^{-3}(12)$ & $1.43 \times 10^{-3}(12)$ & $1.19 \times 10^{-3}(10)$ \\
\hline & 400 & 8057 & $2.48 \times 10^{-4}(2)$ & $2.48 \times 10^{-4}(2)$ & $1.24 \times 10^{-4}(1)$ & $1.37 \times 10^{-3}(11)$ & $7.45 \times 10^{-4}(6)$ & $2.48 \times 10^{-4}(2)$ \\
\hline & 450 & 7958 & $6.28 \times 10^{-4}(5)$ & $2.51 \times 10^{-4}(2)$ & -- & $7.54 \times 10^{-3}(6)$ & -- & -- \\
\hline & Total & 50468 & $4.95 \times 10^{-4}(25)$ & $2.58 \times 10^{-4}(13)$ & $1.78 \times 10^{-4}(9)$ & $9.11 \times 10^{-4}(46)$ & $5.35 \times 10^{-4}(27)$ & $6.54 \times 10^{-4}(33)$ \\
\hline
\end{tabular}

Values in parentheses are no. of macromutants selected

Table.4 Spectrum and frequency of no. of locules per capsule, capsule length, cluster capsule and 1000 seed weight (gm) in Rama and Tillotoma

\begin{tabular}{|c|c|c|c|c|c|c|}
\hline Cultivar & Dose (Gy) & $\begin{array}{c}\text { No. of } \mathrm{M}_{2} \text { seedling } \\
\text { studied }\end{array}$ & Multi locule types & Long capsule types & Clustering types & $\begin{array}{c}\text { More seed wt. } \\
\text { (1000 seeds) types }\end{array}$ \\
\hline \multirow{6}{*}{ Rama } & 250 & 14299 & $4.20 \times 10^{-4}(6)$ & -- & -- & $5.59 \times 10^{-4}(8)$ \\
\hline & 300 & 12926 & $1.08 \times 10^{-3}(14)$ & $7.74 \times 10^{-4}(10)$ & $8.51 \times 10^{-4}(11)$ & $7.74 \times 10^{-4}(10)$ \\
\hline & 350 & 9697 & $2.27 \times 10^{-3}(22)$ & $2.17 \times 10^{-3}(21)$ & $9.28 \times 10^{-4}(9)$ & $2.89 \times 10^{-3}(28)$ \\
\hline & 400 & 8226 & $2.19 \times 10^{-3}(18)$ & $1.22 \times 10^{-3}(10)$ & $9.73 \times 10^{-4}(8)$ & $2.92 \times 10^{-3}(24)$ \\
\hline & 450 & 7518 & -- & -- & -- & $2.93 \times 10^{-3}(22)$ \\
\hline & Total & 52666 & $1.14 \times 10^{-3}(60)$ & $7.78 \times 10^{-4}(41)$ & $5.32 \times 10^{-4}(28)$ & $1.75 \times 10^{-3}(92)$ \\
\hline \multirow{6}{*}{ Tillotoma } & 250 & 15645 & $6.39 \times 10^{-4}(10)$ & -- & -- & -- \\
\hline & 300 & 10425 & -- & -- & $5.76 \times 10^{-} 4(6)$ & $2.21 \times 10^{-3}(23)$ \\
\hline & 350 & 8383 & $1.31 \times 10^{-3}(11)$ & $2.62 \times 10^{-3}(22)$ & $4.77 \times 10^{-} 4(4)$ & $2.62 \times 10^{-3}(22)$ \\
\hline & 400 & 8057 & -- & $1.49 \times 10^{-3}(12)$ & $1.12 \times 10^{-3}(9)$ & $1.86 \times 10^{-3}(15)$ \\
\hline & 450 & 7958 & $1.51 \times 10^{-3}(12)$ & -- & $7.54 \times 10^{-4}(6)$ & $1.76 \times 10^{-} 3(14)$ \\
\hline & Total & 50468 & $6.54 \times 10^{-4}(33)$ & $6.74 \times 10^{-4}(34)$ & $4.95 \times 10^{-4}(25)$ & $1.47 \times 10^{-3}(74)$ \\
\hline
\end{tabular}

Values in parentheses are no. of macromutants selected 

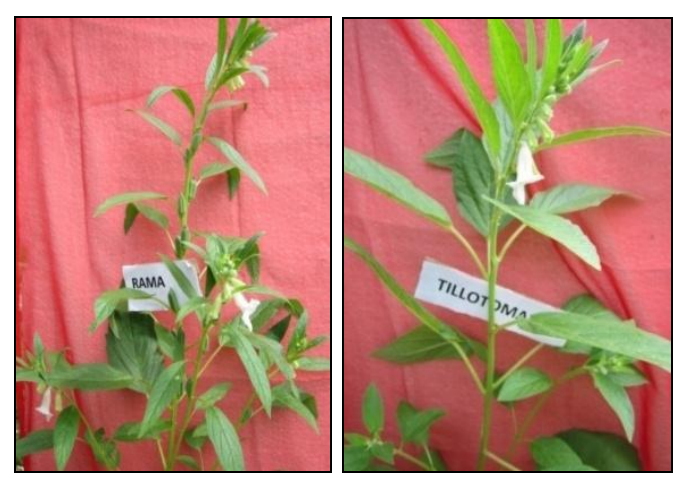

Fig.1 Un-irradiated plant
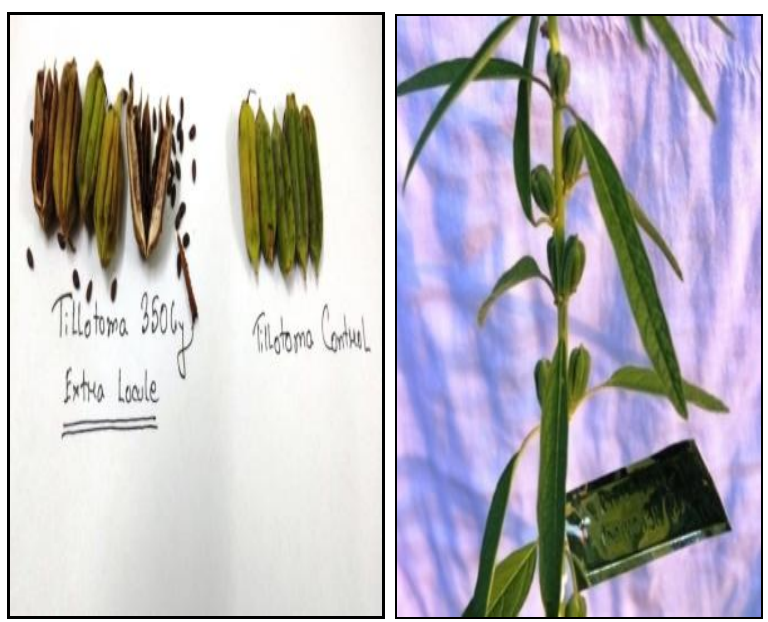

(e)

(f)

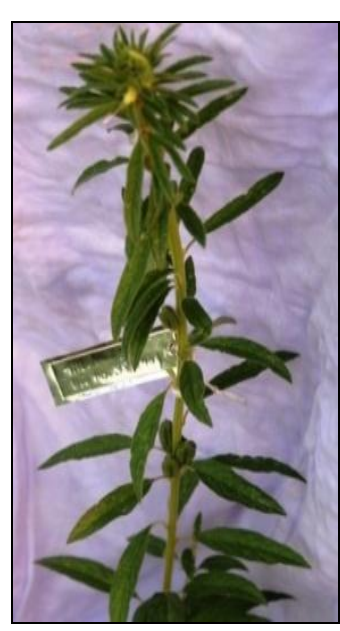

(g)

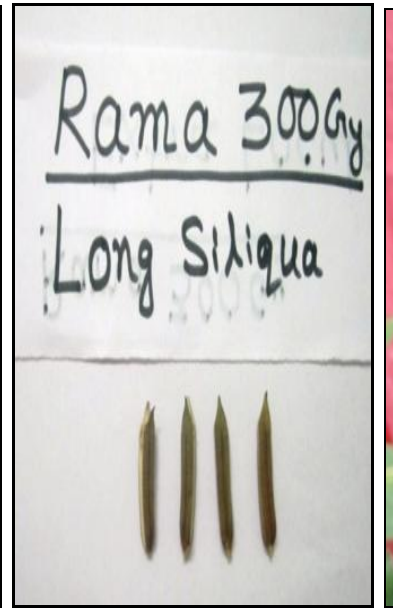

(h)

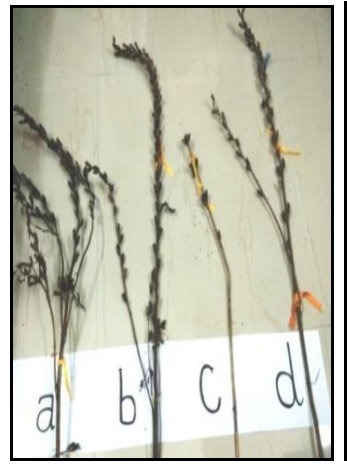

(c)

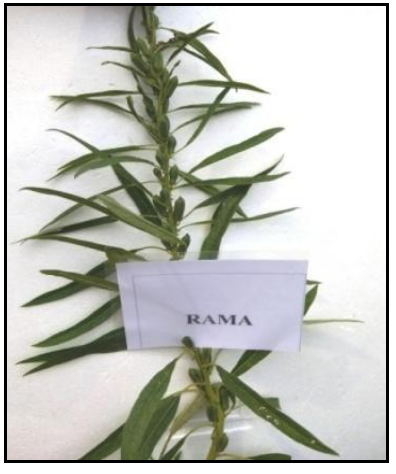

(d)

Fig.2 General view of some macro mutant types. Early matured (a), shattering resistance (b), determinate types(c), monostem (d), multi locule types (e), multi locule types on plant (f) fasciated stem having cluster capsule (g) long capsule (h) cluster types capsule (i) cluster capsule with multi locule (j). 


\section{Monostem types}

54 mutants having single stem were confirmed. The frequency of monostem types was higher in Tillotoma $(5.35 \times 10-4)$ than in Rama (5.13x 10-4) (Table 3) (Fig. 2d). Monostem habit is preferred for mechanized harvest and also much suitable for dense stand under scarce of land for cultivation of sesame. Cagirgan (2001) reported monostem or unbranched with heavy capsule bearing types could be suited to sowing in closely spacedrow under intensive management condition.

\section{More number of capsules per plant}

136 mutants were confirmed from the study of their segregating pattern. The highest frequency was observed in Rama $\left(1.96 \times 10^{-3}\right)$ followed by Tillotoma $\left(6.54 \times 10^{-4}\right)$ (Table 3$)$. Many authors for example, Asthana and Raj (1970), Ganesh and Sakila (1999) stated that number of capsules on main stem and number of capsules on branches showed a high positive direct effect on single plant seed yield in sesame.

\section{Multi locules types}

93 mutants with capsules having six to ten locules were confirmed (Fig. 2e and 2f) whereas 60 mutants from Rama and 33 mutants from Tillotoma background (Table 4). Some of the adult plants from both cultivars were erect and slightly twisted at the top. The stem was flattened like ribbon or phylloclade. Flowers and capsules were born directly on the flat stem without any distinct pedicel. Capsules were mostly 8 to 10 locules (Fig. 2g). In this category cultivar Rama had the highest mutation frequency $\left(1.14 \times 10^{-3}\right)$. Our results confirmed multi locules per capsule could be induced by irradiation which has sound contribution to increasing yield. However, Langham (2007) reported that by converting lines from 2 locules to 4 locules, the seed weight per 4 locule capsules was greater although it didn't double.

\section{Long capsule types}

75 mutants were confirmed under this category with Rama having the highest mutant frequency $\left(7.78 \times 10^{-4}\right)$ followed by Tillotoma $\left(6.74 \times 10^{-4}\right)$ (Table 4) (Fig. 2h). The contribution of this character in plant seed yield may be investigated.

\section{Cluster capsule types}

In this category 53 mutants with up to 3 capsules per leaf axil were selected (Fig. 2i and $2 \mathrm{j}$ ) whereas, the source of parents have only one capsule per leaf axil. Rama had the highest frequency for cluster type mutants $\left(5.32 \times 10^{-3}\right)$ (Table 4). Baydar (2005) screening for the ideal plant type in sesame also found that lines with quadricapsules, tricapsules per leaf axil.

Since it is a recessive character, it is obtained easily by mutagenesis (Cagirgan, 2001).To obtain high-yielding varieties in sesame, multi-capsules per leaf axil has been a good choice as ideal plant type.

\section{More seed weight (1000 seeds)}

1000 seed weight of any crop to be considered as an important yield component. 166 mutants were confirmed from this category having highest frequency in Rama $\left(1.75 \times 10^{-3}\right)$ (Table 4). Maximum mutant types were selected and confirmed for greater seed weight and higher number of capsules per plant which indicate the higher yield of a new plant type and might be increasing the oil quality. The possible cause of aforesaid morphological mutations or macro mutations may be chromosomal aberration, small deficiencies or duplications and obviously gene mutations. 
This study confirmed that, viable mutations induced gross morphological changes in stem structure, phenology, growth habit, capsules shape and sizes and plant architecture. In the present investigation, all mutants were confirmed to bread true in $\mathrm{M}_{3}$ generation. As revealed by the $\mathrm{M}_{2}$ family analysis and the segregation of heterozygous $\mathrm{M}_{3}$ plants, the true mutant traits were: i) randomly found in population ii) recessive and monogenically inherited, which are the basic features of mutation breeding. Although sesame seeds were known to be resistant to gamma radiation, it is not necessary to apply higher doses since medium doses (250 to 350Gy) could be effective to generate viable mutations.

\section{References}

Ashri, A., 1981. Increased genetic variability for sesame improvement by hybridisation and induced mutations. In: A., Ashri (Ed.), Sesame: Status and Improvement. FAO Plant Production and Protection. Paper 29, Rome, pp. 141-145.

Asthana, K.S., and Raj U.K. 1970. Correlation studies in till (Sesamum indicum L.). Allahabad Tmr. 44: 385386.

Baydar, H., 2005. Breeding for the improvement of the ideal plant type of sesame. Plant Breeding. 124:263-267.

Cagirgan, M.I., 2001. Mutation techniques in sesame (Sesamum indicum L.) for intensive management: Confirmed mutants. In: Sesame Improvement by Induced Mutations, IAEA-TECDOC1195, IAEA, Vienna, pp. 31-40.

Cagirgan, M.I., 2006. Selection and morphological characterization of induced determinate mutants in sesame. Field Crops Research. 96: 19-24.

Cagirgan, M.I., 2007. Selection and modification of closed capsule mutants in sesame. In proceedings of Türkiye 7. Tarla Bitkleri Kongresi, 25-27 Haziran 2007, Ataturk Üniversitesi, Erzurum, Türkiye s.408-411 (Abstract in English).

Diouf, M., Boureimai, S., Diop, T. and Cagirgan, M.I. 2010. Gamma raysinduced mutant spectrum and frequency in sesame. Turkish Journal of Field Crops. 15(1): 99-105.

Ganesh, S.K., and Sakila, M. 1999. Association analysis of single plant yield and its yield contributing characters in sesame (Sesamum indicum L.). In: Sesame and Safflower newsletter. J. Fernandez-Martinez (ed.), IAS, CSIC, Cordoba, Spain, pp 16-19.

Gaul, H., 1964. Mutations in plant breeding. Radiat. Bot. 4, 155-232.

Hoballah, A.A., 2001. Selection and agronomic evaluation of induced mutant lines of sesame. In: Sesame Improvement by Induced Mutations, IAEA-TECDOC-1195, IAEA, Vienna, pp. 137-150.

Langham, D.G., 1946. Genetics of sesame III: "Open sesame" and mottled leaf. Journal of Hereditas. 37:149-152.

Langham, D.R., 2007. Phenology of sesame. In: Issues in new crops and new uses. J. Janick and A. Whipkey (Eds.). ASHS, Press, Alexandria, VA, pp.144-182.

Mensah, J. K., Obadoni, B.O., Akomesh, P. A., Ikhajiagbe, B. and Ajibolu, J. 2007. The effects of sodium azide and colchicine treatments on morphological and yield traits of sesame seed (Sesamum indicum L.). African Journal of Biotechnology. 6(5): 534-538.

Sengupta, S., and Datta, A. K. 2005. Induced narrow leaf mutant of sesame (Sesamum indicum L.). Indian Journal of Genetics and Plant Breeding. 65: 59-60.

Silme, R.S., and Cagirgar, M.I. 2010. Screening for resistance to fusarium wilt in induced mutants and world 
collection of sesame under intensive management. Turkish Journal of Field Crops. 15(1): 89-93.

Uzun, B., and Cagirgan, M.I., 2006. Comparison of determinate and indeterminate lines of sesame for agronomic traits. Field Crops Research. 96: 13-18.

Van Zanten, L., 2001. Sesame improvement by induced mutations. Results of the coordinated research projects and recommendations for future studies. Final reports of an FAO /IAEA Coordinated research project organized by joint FAO/IAEA Division of Nuclear Techniques in Food and Agriculture, Vienna, pp 1-12.

Wongyai, W., 1997. Evaluation of stem growth termination in sesame. Sesame Safflower Newsletter. 12: 51-54.

\section{How to cite this article:}

Sruba Saha and Amitava Paul. 2017. Gamma Ray Induced Macro Mutants in Sesame (Sesamum indicum L.). Int.J.Curr.Microbiol.App.Sci. 6(10): 2429-2437. doi: https://doi.org/10.20546/ijcmas.2017.610.287 